\title{
Desenvolvimento regional: uma análise da metade sul do Rio Grande do Sul, Brasil
}

\author{
Regional development: an analysis of the southern half of the State of Rio \\ Grande do Sul, Brazil
}

Virginia Elisabeta Etges - Professora e Coordenadora do Programa de Pós-Graduação em Desenvolvimento Regional na Universidade Santa Cruz do Sul/RGS. E-mail: etges@unisc.br

\begin{abstract}
Resumo
O Ministério da Integração Nacional criou os Programas de Desenvolvimento Integrado e Sustentável de Mesorregiões Diferenciadas, atendendo a um total de 13 regiões no país. Uma delas é a Metade Sul do Rio Grande do Sul. O Fórum da MESOSUL, criado em 2002, tem como objetivo prioritário a implantação e a dinamização de cadeias produtivas alternativas as atividades tradicionais da região, com destaque para a implantação da cadeia de exploração e beneficiamento da madeira. Os dados coletados, entretanto, evidenciam que é a monocultura de espécies exóticas para fins de extração de celulose, atendendo aos interesse de grandes empresas transnacionais do setor, como Stora Enso (sueco-finlandesa) e Votorantim, que se tornou hegemônica na região, promovendo ainda mais a concentração da propriedade da terra e com forte impacto ambiental.
\end{abstract}

\section{Palavras-chave}

Mesorregiões. Forum Mesosul. Florestamento. Desenvolvimento sustentável.

\begin{abstract}
The National Integration Department criated the Integrated and Sustainable Development Programs for Specific Mesoregions, that cover a total of thirteen regions in the country. One such specific Mesoregion is the Southern Half of Rio Grande do Sul. The MESOSUL Forum was founded in 2002, with the purpose of implementation and promotion of productive alternatives to the traditional activities of the region, especially the implementation of the chain of exploitation and wood processing. However, data collected shows, it's not the productive chain of wood that has been implemented but the monoculture of exotic species in order to extract cellulose, as this is the interest of big transnational companies of the sector, such as Stora Enso (FinSweedish) and Votorantim, which has become dominant in the region, further promoting the concentration of land ownership and with significant environmental impacts.
\end{abstract}

\section{Keywords}

Mesoregions. Mesosul Forum. Foresting. Sustainable development. 


\section{INTRODUÇÃO}

O Ministério da Integração Nacional, criado em 1999, tem como uma de suas prioridades a formulação e a condução de políticas de integração e desenvolvimento regional sustentável, de planos e programas regionais de desenvolvimento e o estabelecimento de estratégias de integração das economias regionais. Para tanto, o Ministério assumiu o desafio de promover ações de fortalecimento do pacto federativo por meio do ajuste das ações de desenvolvimento regional, no contexto da integração nacional e no processo de globalização, considerando que:

- O desenvolvimento sustentável pressupõe o desenvolvimento econômico e social, na busca da realização plena da cidadania e, portanto, com incremento da produção com competitividade e equidade econômica e social entre as regiões, contemplando o acesso à infraestrutura logística e à saúde, educação e segurança;

- A integração e o desenvolvimento regional incorporam exigências associadas à melhoria da qualidade de vida, à qualificação do trabalho, ao desenvolvimento científico e tecnológico, e, principalmente, ao respeito à diversidade cultural e espacial, conferindo legitimidade à busca de equidade social;

- O desenvolvimento regional sustentável pressupõe a sustentabilidade ambiental com o uso racional dos recursos naturais e a gestão dos recursos hídricos e dos ecossistemas para o benefício das presentes e futuras gerações.

O Ministério da Integração Nacional reconhece, também, que o aprofundamento da diferenciação territorial e o agravamento da exclusão social resultante da competitividade entre empresas e regiões e do contraste entre o avanço técnico e os baixos níveis de instrução têm favorecido o desemprego, a informalidade e a concentração de renda. Da mesma forma, os fluxos globais de capital, informação, tecnologia e consumo têm criado ilhas de dinamismo no território nacional, redefinindo as relações de dependência entre as regiões.

As ações do Ministério da Integração Nacional voltam-se para o desenvolvimento endógeno, pelo implemento do potencial intra e inter-regional e pelo despertar do cooperativismo entre os governos municipal, estadual e federal, visando à realização de ações integradas e sustentáveis.

Essa política, conhecida como a Política Nacional de Desenvolvimento Regional, teve sua institucionalização por meio de Decreto nº 6047 de 22/02/07, que a elevou à condição de política de governo.
Neste contexto de ações de integração e de desenvolvimento regional, novas regionalizações com escalas espaciais diferenciadas das tradicionais macrorregiões, ganham importância. As mesorregiões diferenciadas surgem, então, como espaços subnacionais de confluência entre dois ou mais estados, ou de fronteira com países vizinhos, com identidade histórica, cultural, social e política e caracterizadas por problemas sociais, institucionais e de dinamismo econômico comuns, em relação às regiões onde se inserem.

As mesorregiões, mais do que um espaço regional de ações integradas de desenvolvimento, têm respaldo nas relações marcadas por características comuns, mercados interdependentes e outras dinâmicas que imprimem nas mesmas uma identidade subnacional.

A cada espaço diferenciado e selecionado do território brasileiro, propõese a implementação de ações que conformam um novo modelo de gestão do território. As mesorregiões são espaços sub-regionais de confluência entre duas ou mais unidades da federação, ou de fronteira com países vizinhos, com identidade cultural, econômica e social própria, com graves carências sociais, institucionais e de dinamismo econômico, menores que as macrorregiões, que necessitam de incentivos e atuação diferenciada do Estado para o desenvolvimento de atividades produtivas e de cooperação.

Assim, no âmbito do PPA 2000-2003, conforme Ferreira, apud Schneider e Lübeck (2003), foram priorizados espaços não contemplados pela política dos Eixos de Desenvolvimento, na medida em que se considerava que as mesorregiões se distribuíam no território brasileiro em espaços complementares àqueles dos Eixos Nacionais de Integração e Desenvolvimento. Neste contexto, o objetivo geral dos Programas das Mesorregiões foi a elevação da qualidade de vida da população residente nas mesorregiões selecionadas, por meio de apoio à implementação de fóruns e de projetos de desenvolvimento local integrado e sustentável, mediante a gestão eficaz e eficiente de suas ações, a capacitação de técnicos e especialistas e o estímulo à estruturação de cadeias e investimentos produtivos.

Já como objetivos específicos, o documento destacava:

1 - promover atividades econômicas sustentáveis, respeitando as características ambientais de cada mesorregião selecionada;

2 - desenvolver os setores produtivos que atendam às necessidades de melhoria das condições de vida da população e fortaleçam a economia das mesorregiões diferenciadas; 
3 - promoção das iniciativas vinculadas à agregação de valor da produção local;

4 - apoiar a implementação de políticas sociais que visem a melhoria da qualidade de vida da população;

5 - criar mecanismos eficientes de articulação ente as diversas esferas do poder público e da comunidade para potencializar os resultados das ações implementadas.

Esses objetivos, por sua vez, traduziam-se em cinco ações que davam forma ao modelo de gestão que traduz, em última análise, a proposta contida nos Promesos:

- capacitação de recursos humanos para a gestão do desenvolvimento local e integrado nas mesorregiões;

- implementação do planejamento para o desenvolvimento sustentável nas mesorregiões;

- mobilização das comunidades mediante o associativismo e o cooperativismo nas mesorregiões;

- constituição do fórum de desenvolvimento sustentável e integrado nas mesorregiões.

Neste quadro, o Ministério da Integração Nacional ${ }^{1}$ concebeu inicialmente 13 Programas de Desenvolvimento Integrado e Sustentável de Mesorregiões para a promoção da integração e do desenvolvimento regional, com base em ações de gestão compartilhada do espaço territorial através do implemento de ações de cooperativismo intermunicipal e interestadual e da integração das políticas públicas. Estas mesorregiões são as seguintes (Figura 1).

Disponível em http://www.mesosul.org.br/nou-rau/document/get.php/183/mesorregiao_ metade_sul_rio_grande_sul.pdf Acesso em: 10 abr. 2010. Ver também ETGES, Virginia Elisabeta. Mesorregiões Brasileiras - O Portal da Metade Sul do RS - Mesosul. Disponível em: http://www.fee.tche.br/sitefee/download/jornadas/2/e4-04.pdf. Acesso em: 15 mar. 2010.

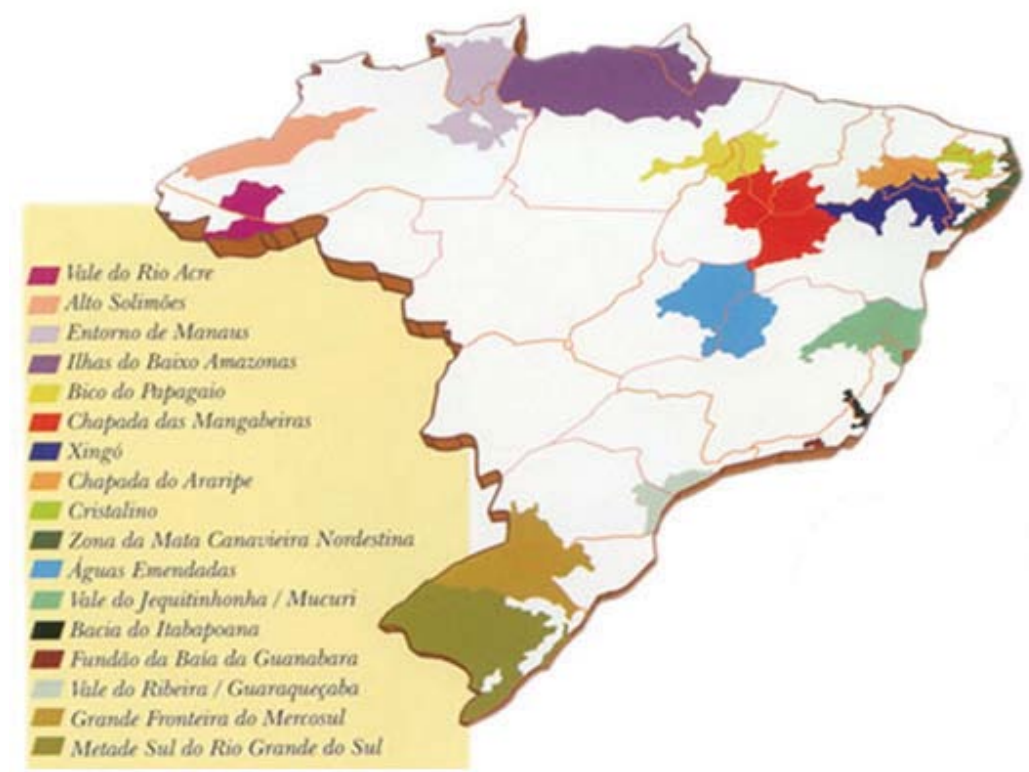

Figura 1. Área de abrangência dos 13 Programas de Desenvolvimento de Mesorregiões Diferenciadas. Fonte: Schneider e Lübeck (2003, p. 37).

No âmbito do Plano Plurianual - PPA 2004/2007, o Governo Federal atribui especial destaque aos Programas de Desenvolvimento Integrado e Sustentável de Mesorregiões Diferenciadas (PROMESO e PROMOVER), sob a condução da Secretaria de Programas Regionais do Ministério da Integração Nacional, selecionando a Mesorregião Metade Sul do Rio Grande do Sul como uma de suas prioridades.

Segundo o Plano, o PROMESO ${ }^{2}$ busca a redução das inaceitáveis desigualdades sociais e regionais, a partir, principalmente, da potencialização dos ativos endógenos tangíveis e intangíveis de mesorregiões diferenciadas.

Seus objetivos são:

- induzir a atuação integrada do Governo Federal em novas escalas especais, preferencialmente em sub-regiões;

- promover a identificação de demandas e soluções à chamada problemática regional com a participação efetiva da sociedade civil que, para tanto, deve estar organizada e legitimamente representada;

- buscar a superação dos desequilíbrios, com base no fomento a todas as regiões que apresentem potencialidades e ativos de capital humano e social,

2 Disponível em: http://www.mi.gov.br/programasregionais/boletim/ . Acesso em: 3 abr. 2010 
parcerias, capacidade de construírem planos e pactos, redes de cooperação entre agentes econômicos, cooperação entre instituições públicas e privadas.

Sendo um Programa que tem como foco a gestão do desenvolvimento amparado no estímulo ao potencial e características econômicas, sociais e culturais próprias de cada região, a operacionalização do PROMESO busca constantemente a organização social e orienta as populações locais sobre as possibilidades concretas de desenvolvimento.

O Programa incentiva ainda a capacitação de pessoas e a criação de bases do associativismo e cooperativismo, visando criar um ambiente propício ao desenvolvimento sustentável das mesorregiões.

Neste cenário também tem destaque o esforço para a implantação de uma infraestrutura mínima necessária ao crescimento econômico das regiões, como obras que não fazem parte de iniciativas de grande porte dos governos e, ainda, facilidades de acesso a financiamentos de baixo custo como, por exemplo, os fundos constitucionais e as agências de desenvolvimento.

O PROMESO proporciona a inserção de ações programáticas decorrentes do exercício da transversalidade que começa a ser colocada em prática na administração pública federal, fazendo convergir esforços tipicamente setoriais para espaços territoriais definidos no âmbito das competências de integração nacional.

Ainda segundo o mesmo documento, o Programa de Promoção da Sustentabilidade de Espaços Sub-regionais foi concebido de forma que seja possível o acompanhamento da evolução dos indicadores socioeconômicos da região, permitindo que as ações governamentais possam ser permanentemente adaptadas às necessidades decorrentes do processo de desenvolvimento.

A estrutura do PROMESO também permite a inclusão de novas áreas a serem identificadas como prioritárias para este tipo de ação, ao mesmo tempo em que experiências bem sucedidas podem deixar de ser objeto do Programa por terem alcançado grau satisfatório e sustentável de incorporação à dinâmica do desenvolvimento nacional.

A criação do Fórum de Desenvolvimento Integrado e Sustentável da Mesorregião Metade Sul do Rio Grande do Sul (Fórum Mesosul), soma-se aos demais esforços fomentados pelo Ministério da Integração Nacional, no sentido de viabilizar um espaço voltado à promoção da integração regional e do desenvolvimento sustentável, amparado no fortalecimento da base socioeconômica local e mesorregional, na inclusão social, no estímulo à participação e à capacidade de organização social, na capacitação dos agentes envolvidos no processo de desenvolvimento e no manejo racional dos recursos naturais.

Conforme Roselani Sodré da Silva, Coordenadora do Fórum Mesosul, não é recente o entendimento da necessidade de criação de uma instância de discussão, de definição e encaminhamento das questões prioritárias para o desenvolvimento da Metade Sul do Rio Grande do Sul. Um organismo que faça a convergência das muitas propostas e ações existentes. Uma estrutura comprometida com a agilização das propostas, disposta a contribuir para avanços mais significativos dos programas e projetos em andamento e que estimule a cooperação entre as diferentes instâncias de governo, instituições não governamentais e a comunidade, provocando a sinergia necessária para alavancar o desenvolvimento desejado (SCHNEIDER; LÜBECK, 2003).

Com esse interesse e visão de futuro é que, em março de 2001, lideranças regionais reunidas na cidade de Bagé, no Rio Grande do Sul, deliberaram pela implementação de ações para um Programa de Desenvolvimento Integrado e Sustentável de Mesorregiões Diferenciadas (PROMESOS), na Metade Sul do Rio Grande do Sul.

Fruto de um intenso debate, viabilizado através da realização de seis seminários regionais ao longo do ano de 2001, que contaram com a participação de aproximadamente novecentas lideranças regionais, foi instalado, na Assembleia Legislativa do Rio Grande do Sul no mês de outubro, o Pré-Fórum de Desenvolvimento Integrado e Sustentável da Mesorregião Metade Sul do Rio Grande do Sul, culminando com a efetiva instalação do Fórum Mesosul em dezembro do mesmo ano, no Auditório da Federação das Associações dos Municípios do Rio Grande do Sul (FAMURS), em Porto Alegre.

\section{CARACTERÍSTICAS DA MESORREGIÃO METADE SUL DO RIO GRANDE DO SUL (MESOSUL)}

Mesorregiões, segundo o Instituto Brasileiro de Geografia e Estatística (IBGE), são áreas individuais que apresentam forma de organização do espaço geográfico definidos por dimensões sociais, naturais e de comunicação própria, que constituem as marcas da sua identidade, resultantes da forma como a sociedade se relacionou com aquele meio ambiente, ao longo do tempo. 
A Mesorregião Metade Sul do Rio Grande do Sul constitui-se em um dos 13 Programas de Desenvolvimento Integrado e Sustentável de Mesorregiões Brasileiras, identificadas pelo Ministério da Integração Nacional, para a promoção da integração e do desenvolvimento regional, com base em ações de gestão compartilhada do espaço territorial, através do implemento de ações de cooperativismo intermunicipal e interestadual e da integração das políticas públicas.

Nos documentos divulgados pelo Ministério, embasando a criação da Mesorregião Metade Sul, lê-se que a mesma é resultante de um processo histórico particular, uma vez que se constituía, até o começo da década de 40 do século XX, na região mais rica do estado do Rio Grande do Sul, com destaque para Pelotas, que era tão ou mais florescente que a capital do estado, Porto Alegre.

Historicamente, a estruturação do núcleo produtivo da Metade Sul do Rio Grande do Sul organiza-se a partir do Porto de Rio Grande (1736), da ocupação do Vale do Jacuí, da conquista das missões e, mais tarde, da cidade de Pelotas, com o estabelecimento das charqueadas e consolidação da cidade como pólo de beneficiamento e escoamento da produção.

No século XX ocorre a substituição desse processo de abate industrial de rebanhos, com a introdução da pecuária ovina, voltada à indústria têxtil. Nas primeiras décadas do século XX aparecem, ainda, os primeiros empreendimentos agrícolas, destacando-se as lavouras tritícolas e orizícolas.

A última grande transformação histórica na mesorregião ocorre com o advento da cultura do arroz em terras úmidas, concomitantemente à diminuição dos rebanhos bovinos e à desvalorização da lã natural frente aos tecidos sintéticos.

A Mesorregião apresenta, portanto, como fatores estruturantes históricos, múltiplos elementos socioeconômicos que se materializam na utilização dos campos, na atividade de pecuária extensiva e na rizicultura irrigada nas várzeas. A dinâmica dessas atividades, a organização do espaço decorrente dos seus habitats particulares e as crises cíclicas definem os comportamentos sociais e demográficos, as formas de concentração de renda e o estilo de consumo da mesorregião.

Os documentos ressaltam ainda que a Metade Sul do Rio Grande do Sul, enquanto espaço sub-regional inserido na região fronteira entre o Brasil, o Uruguai e a Argentina, caracteriza-se por um acentuado processo de perda de dinamismo econômico, oriundo de dificuldades de inserção nos ciclos de expansão da economia brasileira e que, a partir da década de 80 do século passado, a crise que começara na década de 30, com o fim do ciclo das charqueadas em Pelotas, se aprofunda.
Com a desindustrialização e a concorrência promovida pelo Mercosul na agricultura e na pecuária, a região foi perdendo competitividade e dinamismo, chegando a níveis surpreendentes de estagnação, contando com índices de pobreza em diversos de seus municípios que lembram, em muitos aspectos, aqueles das regiões mais atrasadas do país.

A Mesorregião Metade Sul do Rio Grande do Sul, localizada no extremo meridional do país, apresenta a maior área fronteiriça do Mercosul e é composta por 106 municípios, ocupando uma área de 153.879 km², e com uma população residente de cerca de 2.600.000 habitantes, conforme dados do Censo 2000, equivalente a cerca de $52 \%$ do território gaúcho e $25 \%$ da população do estado.

A área da mesorregião abrange oito Conselhos Regionais de Desenvolvimento (COREDES): Campanha, Central, Centro Sul, Fronteira Oeste, Sul, Jacuí Centro, Litoral, e Vale do Rio Pardo, sendo que os últimos dois são abrangidos parcialmente. Os COREDES são instituições de deliberação coletiva da comunidade regional, sob a forma de entidades jurídicas de direito privado, sem fins lucrativos, com prazo de duração indeterminado e que têm por finalidade assessorar o Governo Estadual na definição e planejamento de diretrizes gerais para o desenvolvimento regional e estadual, com o intuito de promover a melhoria da qualidade de vida da população, a distribuição equitativa da riqueza produzida, o desenvolvimento social e econômico com a utilização dos recursos naturais e a preservação do meio ambiente.

Os COREDES são compostos de representantes dos diversos segmentos da sociedade que participam decisivamente das deliberações coletivas que norteiam o desenvolvimento regional e estadual, razão pela qual são verdadeiros pilares de sustentação do novo modelo de gestão regional.

Ainda segundo o Ministério da Integração Nacional, a problemática da Mesorregião da Metade Sul do Rio Grande do Sul pode ser sintetizada nos seguintes itens:

- Crescente perda de dinamismo da economia regional, demonstrada pela progressiva redução de participação no PIB industrial do estado;

- Economia baseada principalmente no setor primário;

- Presença expressiva da grande propriedade e reduzida diversificação de produtos;

- Baixa capacidade de absorção/retenção de mão de obra, gerando êxodo rural e emigração regional;

- Dificuldade histórica de articulação coletiva, seja através de associações ou de atividades comunitárias; 
- Sentimento cultural baseado no individualismo e na ausência de empreendedorismo; e

- Parcela significativa da população do meio rural e urbano vivendo em condições precárias de moradia e saneamento básico.

Estas características tornam-se mais evidentes quando se observa que a região contribui com apenas $16 \%$ do total do PIB do estado. Seus municípios apresentam proporcionalmente, índices de desenvolvimento Humano (IDH) abaixo da média estadual. Por tudo isso, essa região constitui-se hoje, em uma das regiões brasileiras que apresenta dificuldades socioeconômicas reconhecidas, tanto pelo governo estadual, quanto federal

Sua economia se baseia historicamente na produção agropecuária, especialmente o gado de corte e a lavoura orizícola, que são atividades desenvolvidas em grandes propriedades rurais da região, notoriamente concentradoras de capital. Essas atividades já contam, há algum tempo, com mecanismos de investimentos e comercialização consolidados no mercado. Diferentemente deste setor, a maior parte dos empreendimentos de menor envergadura na região têm poucas perspectivas de reprodução socioeconômica, e contam com poucos incentivos.

A falta de incentivos, tanto na capacitação gerencial, como em recursos financeiros, acarreta um baixo dinamismo competitivo dos produtos da região, especialmente aqueles oriundos de atividades empresariais e artesanais de pequeno e médio porte.

Mesmo as iniciativas associativistas, dadas como facilitadoras em termos de comercialização, passam, na região, por dificuldades econômicas e têm pouco acesso aos recursos financeiros, estes geralmente disponíveis para empreendimentos maiores.

Assim, o Fórum Mesosul quer promover a interação dos diversos atores regionais, viabilizando a troca de experiências entre os mesmos, visando o fortalecimento da dimensão horizontal do processo de desenvolvimento da região, com vistas a sua inserção na dinâmica da economia globalizada.

\section{POTENCIALIDADES DA METADE SUL DO RIO GRANDE DO SUL}

Pode-se afirmar que uma das principais potencialidades da Mesosul é a sua posição geográfica e o seu clima privilegiado no contexto do Mercosul. Além disso, apresenta solos de boa qualidade, condições para a exploração turística, abundância de recursos minerais, área tecno-científica de qualidade, grande manancial hídrico, além de portos fluviais e o maior porto da América do Sul, o Porto de Rio Grande; infraestrutura de transportes em crescente melhoria, com destaque para a malha ferroviária.

Segundo o Ministério da Integração Nacional, apud Schneider e Lübeck (2004), a utilização dos recursos naturais, característica intrínseca do tecido econômico e vocação regional, vai continuar a ser determinante na Mesosul. Todavia, cada vez mais o conhecimento, o como fazer, terá mais valor que o produto gerado em si. Neste sentido, é prioritário que a estratégia de aplicação dos recursos públicos tenha como foco a formação de recursos humanos com visão estratégica e capacidade competitiva, seja na iniciativa privada, no setor público ou no terceiro setor. Além da ação transversal de formação e qualificação dos recursos humanos, a prioridade deverá estar na geração de empregos e renda para a população local.

Os estudos do BNDS sobre os segmentos mais dinâmicos da economia nacional identificam de forma consistente cinco setores que mais geram empregos a partir de investimentos setoriais: i) serviços prestados à família (educação, esporte, lazer, saúde, serviços domésticos); ii) agropecuária; iii) madeira e mobiliário; iv) calçados e acessórios; e v) vestuário.

Estudos realizados pelo Ministério da Integração Nacional identificaram, de forma preliminar, oito setores produtivos prioritários para a Mesosul e que deverão servir de base para seleção das propostas de ação, que são os seguintes:

- Setores alternativos/potenciais: florestamento e silvicultura; fruticultura; pesca e aquicultura; cerâmica e rochas ornamentais.

\section{- Setores tradicionais: arroz, carne e leite.}

Sendo a geração de empregos uma das prioridades na Mesorregião Metade Sul, e sendo este segmento o embrião deste aspecto, é mister que este seja considerado ao longo do processo de análise para a seleção das ações a serem implementadas naquela região. Para tanto, é importante que as lideranças regionais não percam de vista que a sustentabilidade do processo de desenvolvimento depende da substituição - mesmo que lenta e gradual - de empregos de baixa qualidade por empregos de maior qualidade, ou seja, maior produtividade advinda de maior qualificação e capacitação dos seus meios de produção.

A reorganização do processo produtivo mediante processo de diversificação econômica para a retomada do desenvolvimento desta região em bases sustentáveis, 
requer uma visão de futuro baseada na ideia de que a atividade econômica de maior valor agregado e recursos humanos talentosos, capacitados e mobilizados atuando em comunidade e cidades saudáveis, e em meio ambiente preservado, atraem empreendimentos econômicos que geram riqueza e pagam bons salários. Os impostos gerados, por sua vez, possibilitam a qualificação e o aperfeiçoamento dos serviços públicos, e os salários pagos geram consumo que abre novas oportunidades de negócios, o que pode ser caracterizado como o círculo virtuoso da melhoria da qualidade de vida.

A partir desta visão, segundo o Ministério da Integração Nacional, é possível identificar três estratégias para a retomada do processo de crescimento da Mesorregião Metade Sul do Rio Grande do Sul, que são:

- Dinamização econômica;

- Cidadania e qualidade de vida;

- Uso sustentável dos recursos naturais.

Para a operacionalização das estratégias selecionadas são sugeridas as seguintes diretrizes:

1.Dinamização econômica

1.1 Diversificação econômica e competitividade;

1.2 Educação para o desenvolvimento;

1.3 Melhoria da infraestrutura regional.

2.Cidadania e qualidade de vida

2.1 Gestão pública inovadora;

2.2 Saúde de qualidade;

2.3 Educação;

2.4 Saneamento básico;

2.5 Erradicação da fome.

3.Uso sustentável dos recursos naturais

3.1 Uso racional dos recursos naturais;

3.2 Valorização do potencial turístico ecológico regional.

A implementação desta estratégia passa necessariamente pela legitimação da proposta junto aos atores do desenvolvimento regional. É recomendado que este processo seja conduzido em sintonia com o Fórum Mesosul e demais lideranças regionais.

Como resultado deste processo, é esperada a proposição de uma agenda institucional devidamente avalizada e compromissada entre os atores. Por ser um instrumento de planejamento, esta agenda deverá estar sempre aberta a recepcionar novas estratégias.

\section{ANÁLISE DOS RESULTADOS ALCANÇADOS}

As ações até aqui realizadas, considerando o que foi proposto no Programa de Desenvolvimento Integrado e Sustentável da Metade Sul do RS (Mesosul), e o que a realidade atual evidencia, permitem identificar duas frentes de ação: uma, expressa no Folder da Mesorregião, sob a responsabilidade do Ministério da Integração Nacional, onde são apresentados os principais projetos desenvolvidos na mesorregião e os recursos destinados a cada um; a outra frente de ação está sob o comando de grupos transnacionais do setor papeleiro, os quais vêm investindo na compra de terras e no plantio de florestas de espécies exóticas (pinus e eucaliptos), com a finalidade de produzir celulose para exportação.

Iniciamos apresentando os projetos implementados pelo Ministério da Integração $\mathrm{Nacional}^{3}$, num total de sete, para os quais foi previsto o investimento de um total de $\mathrm{R} \$ 6.552 .954,00$.

- Implantação, ampliação e reforma de viveiros florestais e fomento ao florestamento e ao reflorestamento (2003)

Busca promover, a partir de ações voltadas à viabilização do potencial florestal, a estruturação da cadeia produtiva da madeira e móveis. Os principais beneficiários são as cooperativas e as associações de pequenos e médios agricultores rurais e indústrias da cadeia madeira e moveleira, propondo para estes uma alternativa socioeconômica e ambiental com um viés socioeconômico, gerando emprego e renda, bem como alternativa de diversificação produtiva, além de importante aspecto ecológico de recomposição de matas nativas nas áreas de proteção permanente e reserva legal das propriedades da região.

Valor investido pelo MI: R\$914.000,00.

Disponível em: http://www.mi.gov.br/programasregionais/boletim/. Acesso em: 20 abr. 2010. 
- Implantação de núcleos de indução e diversificação produtiva na Metade Sul do Rio Grande do Sul para agricultores assentados e associados com base na fruticultura (2004)

A fruticultura apresenta-se como uma boa alternativa de geração de emprego e renda para a região. O objetivo principal deste projeto é desenvolver em bases sustentáveis a produção de fruticultura sul como alternativa de geração de renda e ocupação de mão de obra dos agricultores assentados e dos agricultores associados como meio para o desenvolvimento regional. Serão implantados pomares para atender no mínimo 750 produtores, buscando fixar o homem no campo e garantindo produto de qualidade para as indústrias e as empresas processadoras de frutas da região.

Valor investido pelo MI: R\$2.761.448,00.

- Lapidação e artesanato mineral (2005)

Este projeto tende a valorizar o potencial produtivo até então pouco explorado em duas regiões: Quaraí e São Martinho da Serra, bem como municípios vizinhos. Seu intuito é fomentar o desenvolvimento sustentável dos garimpos de ametista, citrino e outros minerais, por meio do aporte de máquinas e equipamentos de lapidação e artesanato mineral para beneficiamento da matéria-prima junto às fontes de produção, propiciando assim agregação de valor à matéria-prima, bem como apoiar os processos coletivos de aprendizagem, produção e comercialização, por meio de sistemas de cooperação mútua.

Valor investido pelo MI na região de São Martinho da Serra: R\$ 492.000,00.

Valor investido pelo MI na região de Quaraí: R\$467.612,00.

- Fortalecimento da rede de sementes agroecológicas - gerando trabalho e renda para a agricultura familiar brasileira (2005)

O projeto visa a consolidar em bases sustentáveis a cadeia produtiva e a rede de sementes agroecológicas, por meio da aquisição de equipamentos e máquinas necessárias, bem como da qualificação e do treinamento permanente agricultores e técnicos envolvidos neste processo. Representa, ainda, uma perspectiva estratégica de recuperar a autonomia da agricultura familiar brasileira, fortalecendo e consolidando a proposta de produzir suas próprias sementes, com a cadeia agroindustrial totalmente coordenada por cooperativas e associações de agricultores familiares, garantindo escala de produção, qualidade, diversidade, agregação de valor e renda.

Valor investido pelo MI: R\$449.799,00.
- Produção de leite como instrumento de inclusão social do pequeno produtor $(2005)$

Este projeto busca contribuir com o desenvolvimento sustentável do setor leiteiro pela transformação da matéria-prima em produto industrializado, no município de Santa Vitória do Palmar. O aporte de recursos foi para a compra de máquinas e equipamentos para a instalação de uma microusina de leite, o que permitirá agregar valor e incentivar o associativismo e o cooperativismo dos beneficiários, gerando conhecimentos e reduzindo custos de produção da atividade para a pequena propriedade

Valor investido pelo MI: R\$142.000,00.

- Centro gestor de inovação da rede moveleira

O projeto visa a criar um ambiente capaz de provocar a mudança cultural dos diferentes elos da cadeia produtiva da madeira-móveis, por meio da construção de uma rede com empresas produtoras de móveis. Ele ainda busca agregar valor aos produtos dessas empresas por meio da inovação, da introdução de produtos no processo produtivo, do design, da capacitação das empresas em processo produtivo, da prospecção de mercado, assim como da atuação integrada entre empresas com certa aproximação geográfica. Reforça o trabalho associativo e das redes de cooperação, bem como qualifica profissionais para desenvolvimento de produto, por meio de uma oficina para realização de protótipos com respectivos ensaios físico-mecânicos, em parceria com atores deste ramo na região.

Valor investido pelo MI: R\$858.095,00.

- Centro mesorregional de vitivinicultura (2006)

Este projeto destina-se a criar uma estrutura para o apoio tecnológico que reduza o risco de baixa competitividade de empreendimentos vitivinícolas de pequeno porte da mesorregião. Nela apresentam-se empreendimentos que começam a se consolidar fisicamente, mas deparam com limitações técnicas, tanto na obtenção de uvas quanto no processamento e posterior comercialização do vinho e do suco. Dessa forma, estão previstas ações de acompanhamento técnico e capacitação de produtores e técnicos, com abrangência regional em viticultura e enologia, a partir da implantação de um Centro Mesorregional de Vitivinicultura, compondo, assim, a estrutura de apoio às iniciativas já existentes de produtores reunidos em associações ou cooperativas.

Valor investido pelo MI: R\$960.000,00 
Esses projetos foram implementados, mas ainda não há avaliação dos impactos e dos resultados efetivamente alcançados.

Já a ação de grupos transnacionais do setor papeleiro, como Stora Enzo e Votorantim, têm sido bem mais agressivas, o que pode ser observado através dos seguintes fatos, conforme Amaral (2008):

- concentração da propriedade da terra, na medida em que o projeto do setor papeleiro prevê a plantação de um milhão de hectares estado no Rio Grande do Sul;

- aumento da pobreza na região, pelo fato do florestamento indiscriminado suprimir oportunidades e potencialidades, por não valorizar as aptidões naturais produtivas e a cultura da região. O exemplo do que acontece no Uruguai na geração de emprego neste setor é esclarecedor: o censo de 2000 mostra que a cada mil hectares são gerados 4,5 empregos naquele país. Ou seja, um emprego para cada 220 hectares. Um estudo sobre empregos realizado no Espírito Santo nas regiões de atuação da Aracruz aponta que na época em que buscava financiamento, a empresa afirmava que cada hectare geraria em média quatro empregos diretos. Com seus 247 mil hectares na época, deveria gerar 988 mil empregos. Mas, até 2004, tinha gerado apenas dois mil empregos;

- redução da faixa de fronteira, projeto proposto pelo senador Sérgio Zambiasi (PTB) e do deputado federal Vieira da Cunha (PDT), além de beneficiar a indústria da celulose, também vai permitir outras formas de exploração no estado, como o uso desenfreado do Aquífero Guarani.

- "anulação", por parte do governo do estado do RS, do Zoneamento Ambiental, elaborado pelos técnicos da Fundação Zoobotânica e da Fundação de Proteção Ambiental (Fepam) em 2007, o qual estabelecia limites para o plantio de florestas exóticas por Unidades de Paisagem Natural, dentre outras indicações;

- "criação" de novo zoneamento, aprovado em 2008, que atende explicitamente aos interesses das papeleiras Stora Enso e Votorantim. Para o Instituto brasileiro do Meio Ambiente e dos Recursos Naturais Renováveis (Ibama), este zoneamento serve somente para legitimar os procedimentos de licenciamento da atividade de silvicultura e produção de celulose, sem o planejamento ambiental adequado à magnitude dos empreendimentos propostos e já em implantação. Ele, para se configurar como instrumento eficaz para o planejamento da silvicultura, deveria considerar, no mínimo, os índices de vulnerabilidade das Unidades de Paisagem Natural (UPN), percentuais de uso em cada UPN e os tamanhos e distâncias entre os maciços de árvores.
Além dessas constatações, segundo Alonso (2009), a disseminação da monocultura através do florestamento impede, acima de tudo, que a região, secularmente estagnada pela falta de diversificação das estruturas produtivas, restritas basicamente à produção de carne e arroz, promova o que ela mais precisa: diversificar as atividades agrícolas e agropecuárias. Ou seja, a solução para essa região deveria ser a antítese da monocultura, que é basicamente o que ela sempre teve e o que a levou ao estado de penúria em que se encontra na atualidade.

\section{CONSIDERAÇÕES FINAIS}

Com a implementação do Fórum Mesosul pretendia-se fomentar e ampliar a capacidade da sociedade regional na construção do desenvolvimento econômico e social sustentável em longo prazo, baseado na ampliação da competitividade em padrões internacionais, com um papel diferenciado de articulação no âmbito do Mercosul. Estas ações deveriam resultar na promoção de atividades econômicas dinamizadoras de postos de trabalho e empregos produtivos e bem remunerados para os moradores da região, possibilitando uma base econômica sólida para o enriquecimento de todos os aspectos da vida na Metade Sul. A Mesosul deveria ser reconhecida como uma região privilegiada para se fazer negócios.

O levantamento sistemático das demandas coletivas da mesorregião, tanto de caráter social como de infraestrutura, e seu encaminhamento às diversas instâncias de governo, foi realizada a partir da implementação de estratégias de planejamento participativo, que envolveram as instituições públicas e privadas e organizações da sociedade civil organizada, contribuindo, dessa forma, para a capacitação de recursos humanos para a gestão do desenvolvimento.

A articulação e a participação efetiva dos atores sociais da mesorregião também deveria ter como resultado a criação e institucionalização de um Fundo Regional para o Desenvolvimento da Metade Sul do Rio Grande do Sul e a criação de uma Agência de Desenvolvimento da Metade Sul do Rio Grande do Sul.

Além destas iniciativas, foi criado também o Portal Mesosul (www.mesosul. org.br), que se somou a estes esforços, na medida em que deveria viabilizar a implementação de um sistema de difusão de informação e de conhecimento na mesorregião, conectada à rede mundial de comunicações (Internet) permitindo a interação entre os diversos atores regionais com vistas à promoção do desenvolvimento da região. 
Entretanto, apesar de todas essas iniciativas, a realidade evidencia que a implementação do que foi proposto no Programa de Desenvolvimento Integrado e Sustentável da Metade Sul do Rio Grande do Sul está longe de alcançar seus objetivos. Necessário se faz investigar e analisar criteriosamente esse processo, para que se possa contribuir na implementação de políticas públicas voltadas ao desenvolvimento de regiões economicamente estagnadas, como é o caso da Mesosul.

\section{REFERÊNCIAS}

ALONSO, J. A. F. O que vai ser da metade sul? FEE - Informativo João de Barro. Disponível em: http://www.apcefrs.com.br/jb/2009/fevereiro/04.pdf. Acesso em: 12 abr. 2010.

AMARAL, F. Metade Sul do RS: Esquecida pelo governo, suprimida pela celulose. São Leopoldo: IHU On-line - Instituto Humanitas Unisinos da Universidade do Vale do Rio dos Sinos, 2008.

ETGES, V. E. Mesorregiões Brasileiras - O Portal da Metade Sul do RS Mesosul. Disponível em: http://www.fee.tche.br/sitefee/download/jornadas/2/ e4-04.pdf. Acesso em: 15 mar. 2010.

\section{LÜBECK, E.; SCHNEIDER, F. M. Programa de Desenvolvimento Integrado} e Sustentável da Mesorregião Metade Sul. Santa Maria: Pallotti, 2003.

POLÍTICA NACIONAL DE INTEGRAÇÃO E DESENVOLVIMENTO REGIONAL. Competitividade com Equidade e Sustentabilidade. Brasília: Ministério da Integração Nacional, 2002.

RELATÓRIO DO FORUM MESOSUL. Período Jan/2002 a jul/2004. Brasília: Ministério da Integração Nacional/Corede Sul.

PROGRAMAS DE DESENVOLVIMENTO REGIONAL - PPA 2004-2007. Ministério da Integração Nacional. Brasília, 2004. Disponível em: http://www. mi.gov.br/programas/desenvolvimentoregional/index.asp. Acesso em: 04 abr. 2010.

Texto submetido à Revista em 6.7.2010

Aceito para publicação em 13.11.2010 